\title{
Collective Learning and the Theory of the Firm
}

\author{
NATHALIE LAZARIC AND EDWARD LORENZ
}

\section{Introduction}

One of the most striking post-war developments in the field of economics has been the way the increasing dominance of the neoclassical paradigm has been associated with efforts to widen its span in terms of the range of questions and topics addressed. Gary Becker's (1964) use of the standard tools of neoclassical economics to treat such problems as the organisation of family life or altruism illustrates admirably the post-war trend. This feature of contemporary economics arguably marks a break with the early decades of the 20th century, when the failure of neoclassical economists to bring under their purview the institutional and social framework of economic transactions allowed such economists as Veblen, Commons and Mitchell to carve out a place for an alternative, non-neoclassical approach.

The "new institutional economics", associated notably with the work of North and Thomas (1973) and Williamson $(1975,1985)$, stands in a somewhat ambiguous relation relative to this contrast between pre and post-war periods. On the one hand, one finds clearly expressed in this literature a desire to use the mainstream language of optimisation in analysing the determinants of institutions and organisational arrangements. On the other hand, this literature has taken on-board certain concepts developed as part of a critique of the standard model of rational man, notably Simon's notion of bounded rationality. Favereau (1989), in his discussion of this literature, has coined the term, "the standard theory extended" (la théorie standard étendue) to underscore that it amounts more to a modification of the standard neoclassical approach than to a radical break. On his account, the ultimate aim, as with the agency and incomplete contracts literatures, is to carry over the logic of maximisation to the study of such diverse phenomena as institutions, social norms and conventions, whose characteristics are accounted for endogenously in terms of optimal contractual arrangements.

Favereau's remarks raise the question of whether the new institutionalism is truly in keeping with the spirit of Simon's critique of optimising rationality. In the 1950s, Simon's concern to express formally the properties of decision-making subject to computational constraints led him, in collaboration with Newell, to develop protocol analysis as a means of identifying the rules of thumb individuals use to reduce cognitive burdens and the heuristics they adopt in their problem-solving efforts. The insights gleaned from these laboratory interview techniques were then formalised in the form of computer simulations, such as the well-known "General Problem Solver", which was applied to solve various puzzles (Newell and Simon, 1961, 1972). Simon's work, of course, has 
been the subject of lively debate and criticism, notably by Dreyfus (1992), who has challenged the implicit assumption that all intelligent behaviour can be accounted for in terms of rule-governed mental processes. Within the field of economics, though, contemporary debate has been centred less on this limiting aspect of Simon's research, than on what his focus on rule-guided behaviour and problem-solving activity implies for the standard model of rational man.

Arguably the key shift in Simon's approach was his recognition that choice is necessarily exercised within a particular framework and that such frames are not given but rather are constructed by the actors. When a situation is a repeatedly encountered one, it may give rise to a well-structured definition of the problem including a repertory of responses and a rule for selecting the appropriate response from amongst the repertory. This amounts to routine behaviour. When the situation is a novel one, however, there will first be a certain amount of search and problem-solving activity in order to define the situation and then further learning activity of this sort designed to develop an appropriate response (March and Simon, 1958, pp. 158-163). In focusing on frames of reference and on the cognitive limitations that shape their construction, Simon shifted the debate away from the question of the substantive rationality of choice, and rather placed it on the procedural rationality of decision-making or on the learning processes whereby the frames and rules which determine choice are devised.

In shifting the focus of inquiry to these procedural issues, Simon's work, at least implicitly, brought into question the way knowledge is conceived in standard economics. Since what individuals know depends on the frames they operate within, it no longer is tenable to conceive of knowledge in terms of given information partitions, where the only distinction between agents is how coarse or fine the partitions are. Moreover, the point being made here should not be confused with the proposition that information may be asymmetrically distributed between agents. The idea is that knowing something requires active interpretation of information, and this knowing may be highly unevenly distributed despite the fact that access to information is symmetric or equal. Simon (1999) has recently given recognition to the complexity of the issue, in observing that in their daily operations, organisations are confronted with considerable uncertainty around establishing procedures for creating, sharing and stocking knowledge.

The relevance of the distinction between information and knowledge is far from being accepted by all economists. Recognition of this distinction can raise serious methodological problems. For example, it is not at all clear that one can construct meaningful quantitative measures of knowledge. One cannot hope to treat knowledge like any other good and define a measure by adding up the value of market transactions. It is true that intellectual property is occasionally bought and sold. However, many, if not most, knowledge transactions bypass the market. Much knowledge is developed and retained within the firm, and knowledge exchange may occur through partnership or network relations that are not subject to market transactions.

Problems of describing and measuring knowledge arise if one takes seriously the notions of distributed and tacit knowledge. Distributed knowledge, for example, expresses the idea that no individual can fully describe an organisational practice or routine, since it arises through the interaction of the only partially articulated knowledge of multiple individuals (Cohen et al., 1995, p. 17). If the notion of tacit knowledge is taken 
to mean that some relevant bits of knowledge are not formally specifiable, and not just that they are not being specified, then our efforts to articulate what that knowledge is will inevitably be incomplete.

In this special issue on collective learning and theories of the firm, we make no claim to have addressed, much less to have provided adequate answers to, the full range of problems posed by the economic analysis of knowledge and learning. Rather, our more modest ambition is to consider how various theories of the firm have gone about integrating these problems and issues into their analysis. Thus, Kirsten Foss and Nicolai Foss examine the relation between organisational structure and learning in the context of a comparison of the 'knowledge-based approach' (KBA) and 'organisational economics' (OE). KBA researchers, associated with such diverse perspectives as the competencebased, the resource-based and the dynamic capabilities approaches, have been wholehearted in their criticism of OE authors for their focus on problems of agency problems and asymmetric information, to the neglect of the learning processes which create knowledge assets. Foss and Foss defend the provocative view that KBA authors, while placing much stress on learning and the development of competences, have by and large been less than successful in defining what are the relevant real-world phenomena to be analysed, in clarifying the theoretical background knowledge against which these phenomena are challenges, and in providing rigorous explanations of the relevant phenomena.

Foss and Foss then go on to develop the view that ideas associated with the efficient allocation of property rights developed in the $\mathrm{OE}$ tradition may be used for this purpose. More specifically, they argue that these ideas can be used for establishing an understanding of organisational learning in the form of experimental activity within firms, and for connecting the results of such experimentation to firm organisation and competitive advantage. Harking back to Simon's work on decomposable systems (Simon and Ando, 1961), they suggest, much in the spirit of Coase, that firms may prove superior to the market in settings where the necessary conditions for efficient experimenting, such as the ability to define system boundaries, isolating the experiment from outside disturbances, and "guiding" the experimental activity, are not met. They note that market failure may be encountered in connection with all three conditions, since with bounded rationality, agents may disagree about system boundaries and how to isolate the system from outside disturbances. Under such conditions, the use of authority, taken to mean managerial prerogatives to redefine and reallocate rights among team members, may be the costeffective way of organising the learning activity.

Brian J. Loasby is similarly concerned with the problem of learning, in a paper which draws inspiration from Kelly's (1963) work in psychology. Loasby considers to what extent individuals organise their knowledge by means of interpretative frameworks whose purpose is not to produce a simplified version of reality, but rather to render consistent the diverse elements of information they are confronted with. In this approach to cognition, the structure of human knowledge is not given randomly but rather results from the cognitive frameworks within which individuals imagine coherent responses to problem situations.

This process is not confined to the individual level but also concerns the collective or organisational level. The organisation of manufacturing work can be seen as an archetypal example of a context where process determines content. More precisely, the 
division of labour engenders a division of knowledge and a cognitive framework which serves to structure manufacturing activities. Beyond the question of achieving productivity gains, the division of labour structures the way individuals go about collectively solving problems and it may act to lock them into particular interpretative frames, thus placing limitations on their ability to extend the breadth of their knowledge and problemsolving activity. Penrose (1959) implicitly raised this issue in considering how the ability of firms to extend the range of their activities is constrained not only by the compatibility of externally available knowledge with internal resources and organisation, but also by limitations on entrepreneurial judgement and imagination. The entrepreneur may find himself a prisoner of a given vision of the world that limits his ability to seize opportunities for growth, and it may require periods of industrial restructuring to induce him to question and modify his initial beliefs and assumptions.

In this context, a key question raised by Loasby concerns the circumstances under which individuals might escape from the established frames of reference which limit their interpretations of the world. The metaphor of Adam Smiths pin factory provides a good example of how a given structure of collective knowledge may create obstacles for imagining alternative combinations of knowledge that are at odds with established cognitive frameworks.

Nathalie Lazaric in her contribution focuses on the role of routines, rules and habits in collective learning processes. She takes up this question at the epistemological and ontological levels as well as from a comparative historical perspective. Thus, in the 'old' institutional economics of Veblen (1914) the notions of routine and habit are employed interchangeably. For Veblen, habits of thought which are more or less widely adopted in society constitute institutions that structure the cognitive capacities of individuals. Veblen's methodology consists in an effort to trace historically the evolution of these cognitive frames or schemes. Simon, on the other hand, confronted with a similar problem of accounting for routine behaviour turned to laboratory experiments and computer simulation as a means of identifying the rules and heuristics that individuals adopt in their efforts to solve puzzles and games, such as chess. Nelson and Winter (1982) shifted the terms of the debate by focussing on certain cognitive properties of routines, notably their tacit character, and by stressing the idea that routines constitute the memory of the organisation in the sense that one's knowledge is activated through one's daily routine practice. Their work has kindled a lively debate around the nature of routines, which can be described in terms of the opposition between ethnological approaches, inspired in part by the work of Veblen, and more experimental approaches in the tradition of Simon's work in artificial intelligence.

As Lazaric shows, this methodological division can be seen as corresponding to the distinction often made in the contemporary literature between routines understood as rules or abstract representations, and routines understood as behaviour which may be an expression of such representations. Lazaric uses this distinction as a point of departure for a fuller discussion of the epistemological issues at stake in the current debate. However, she also argues that one needs to go beyond the question of epistemology and recognises that the processes which change routines involve both a cognitive and a political dimension. Addressing the way the two dimensions co-evolve remains a major empirical and theoretical research challenge that should not be underestimated. 
Pierre André Mangolte arrives at a similar conclusion by a different route. His principal concern is to characterise the way behavioural economics has sought to incorporate conflict and political processes into the analysis of organisations and their learning dynamics. Thus, for Simon (1947) and for Cyert and March (1963), organisational equilibrium is inevitably threatened by conflict. Organisations respond to this threat by establishing authority and control mechanisms designed to promote identification with the goals of the organisation and to foster sentiments of loyalty. This view of the matter accounts for the fact that these authors adopt a conception of the firm as a coalition involving a continuous bargaining process allowing for a temporary resolution of conflicts of interest. From this perspective, successful coordination within the organisation is far from automatic and is necessarily something that has to be continuously nurtured and constructed.

Nelson and Winter (1982), in discussing the nature of routines, proposed the hypothesis of an organisational 'truce'. This assumption allows them to examine the way the members of the organisation activate their routines while putting to the side the question of conflict. Routines can be treated in an a-political manner, in terms of the knowledge that is embodied within them and which is activated through the members' daily productive activities. Mangolte arrives at the conclusion that the logic of conflict is not that of organisational learning, and that the two are based on different types of dynamic processes. Nonetheless he questions the validity of the 'truce' hypotheses. The question here is whether it is valid to divide the organisation into two distinct parts, thus separating cognitive skills and aptitudes from the political and relational context in which they unfold. The problem of organisational change, or of the processes that change routines, clearly shows why the cognitive and political dimensions should be seen as two sides of the same coin.

Mangolte's conclusion provides the starting point for concluding this special number by Edward Lorenz's paper. In his contribution, Lorenz aims to provide some programmatic suggestions for conceptualising organisational learning in a manner that does justice to both its cognitive and political dimensions. Lorenz takes his inspiration from J.R. Commons' (1934) evolutionary theory of institutional change. That Commons' work has much of interest to say about the political dimension of organisational behaviour comes as little surprise, for it is well known that conflicts and their resolution are at the heart of Commons' conception of the processes which change customary rules and practices. While accepting that Commons has little to say about internal cognitive processes and mechanisms, Lorenz nonetheless argues that his approach is fully compatible with an analysis that does attach importance to analysing the role of the relational and organisation-specific knowledge individuals need to participate in collective tasks.

Lorenz emphasises a key distinction Commons makes in his analysis which is missing in the contemporary literature on routines and organisational learning, namely the distinction between habit and custom. By habit, Commons is referring to the individual learning processes which account for the development of routinised behaviour characterised by both automaticity and tacitness. These latter features can be accounted for by the need to reduce cognitive load, in the sense that they free up intellectual resources for the 'limiting' factors requiring discretionary decision-making. Custom, on the other hand, refers to the collective sanctioning processes which make particular action patterns more 
likely. The basic idea is that sanctions or the threat of sanctions channel individual learning process in directions that are socially acceptable. Thus, in making the distinction between habit and custom, Commons links a cognitive dimension of routine behaviour to a wider social and political context and thus provides some programmatic advice for a more integrated approach to the study of routines. Lorenz concludes by observing that the approach remains partial, since it addresses the relational and organisation-specific knowledge members require to cooperate, but neglects that other building block of routines, namely relatively modular knowledge such as that needed to operate a standard machine tool or undertake maintenance of standard equipment. He suggests that recent work on socially dependent cognition associated with such writers as Lave (1988) and Hutchins (1995) offers a possible route for integrating cognitive skills into the analysis in a manner that is consistent with Commons' focus on the institutional and social determinants of behaviour.

The five papers passed in review above have all been centrally concerned with behaviour shaped by rules and institutions and with the learning processes that transform and change such behaviour. Despite their significant differences, they have each sought to illuminate the nature of economic co-ordination mechanisms which do not conform to the standard neo-classical treatment of the price mechanism. This common interest in behaviour guided by rules, habits or conventions can, of course, be linked to an earlier tradition and notably to the writings of such 'old' institutionalists as Veblen and Commons, who drew on the pragmatic philosophy of Peirce and Dewey to develop a vision of human agency motivated by habit and custom as opposed to optimising choice (Hodgson, 1997). Similar concerns with the limits of rationality can be seen in Keynes' (1937) discussion of conventions or behavioural regularities that are common to a population of agents. By bringing into relief and by comparing a number of contemporary approaches to these issues, this special number has sought to make a contribution to the revival and further development of a behaviourally realistic economic that takes cognitive limits on rationality as its starting point.

\section{References}

Becker G. (1964) Human Capital: A theoretical and empirical analysis, Columbia University Press, New York.

Cohen M., Burkhart R., Dosi G., Egidi M., Marengo L., Warglien M., Winter S. (1995) Routines and Other Recurring Action Patterns of Organizations: Contemporary research issues, unpublished working paper, Santa Fe.

Commons J.R. ([1934] 1990) Institutional Economics: Its Place in the Political Economy, Transaction Publishers, New Brunswick.

Cyert R., March J. (1963) A Behavioral Theory of the Firm, Prentice-Hall, Englewood Cliffs.

Dreyfus H.L. (1992) What Computers Still Can't Do: A critique of artificial reason, MIT Press Cambridge, MA.

Favereau O. (1989) Marchés internes et marchés externes, Revue Économique 40 no. 2, pp. 273-328.

Hodgson G. (1997) The ubiquity of habits and rules, Cambridge Journal of Economics 21, pp. 663-684. 
Hutchins E. (1995) Cognition in the Wild, MIT Press, Cambridge, MA.

Kelly G.A. (1963) A Theory of Personality, W.W. Norton, New York.

Keynes J.M. (1937) The General Theory of Employment, Quarterly Journal of Economics 51, pp. 209-223

Lave J. (1988) Cognition in Practice, Cambridge University Press, Cambridge.

March J., Simon H. (1958) Organizations, Wiley, New York.

Nelson R., Winter S. (1982) An Evolutionary Theory of Economic Change, Harvard University Press, Cambridge, MA.

Newell A., Simon H. (1961) Computer Simulation of Human Thinking, Science 134, pp. 2011-2017.

Newell A., Simon H. (1972) Human Problem Solving, Prentice Hall, Englewood Cliffs.

North D., Thomas R. (1973) The Rise of the Western World: A new economic history, Cambridge University Press, New York.

Penrose E. (1959) The Theory of the Growth of the Firm, Wiley, New York.

Simon H. (1947) Admistrative Behavior, Macmillan, New York. French translation "Administration et processus de décision”, Economica, Paris, 1983.

Simon H. (1999) The Many Shapes of Knowledge, Revue d'Économie Industrielle, no. 88, pp. 23-39.

Simon H., Ando A. (1961) Aggregation of Variables in Dynamic Systems, Econometrica 29, pp. 111-138.

Veblen T. (1914) The Instinct of Workmanship, and the State of the Industrial Arts, August Kelly, New York.

Williamson O. (1975) Markets and Hierarchies, Free Press, New York.

Williamson O. (1985) The Economic Institutions of Capitalism, Free Press, New York.

to access this journal online:

www.edpsciences.org 
